\title{
Goldilocks, the Three Bears and Intensive Care Unit Utilization: Delivering Enough Intensive Care But Not Too Much. A Narrative Review
}

\author{
Laura C. Myers · Gabriel Escobar • Vincent X. Liu
}

To view enhanced content go to www.pulmonarytherapy-open.com

Received: November 11, 2019 / Published online: January 3, 2020

(C) The Author(s) 2020

\section{ABSTRACT}

Professional societies have developed recommendations for patient triage protocols, but wide variations in triage patterns for many acute conditions exist among hospitals in the United States. Differences in hospitals' triage patterns can be attributed to factors such as physician behavior, hospital policy and realtime conditions such as intensive care unit capacity. The patient safety concern is that patients evaluated for admission to the intensive care unit during times of high intensive

Enhanced digital features To view enhanced digital features for this article go to https://doi.org/10.6084/ m9.figshare. 11322857.

\section{C. Myers $(\square)$}

Division of Pulmonary and Critical Care Medicine, Massachusetts General Hospital, Boston, MA, USA e-mail: lcmyers@partners.org care unit capacity may have adverse outcomes related to delays in care. Because standardization of a national triage policy is not feasible due to differing resources available at each hospital, local guidelines should prevail that take into account hospitals' local resources. The goal would be to better match intensive care unit bed supply with demand.

Keywords: Acute respiratory illness; Critical care; Intensive care unit; Patient triage; Resource utilization

\section{G. Escobar · V. X. Liu}

Division of Research, Kaiser Permanente Northern

California, Oakland, CA, USA 


\section{Key Summary Points}

There is wide variation in the patterns of use of intensive care unit beds across hospitals in the United States. There is also variation between the United States and the United Kingdom.

An array of interrelated factors influence patient triage decisions, including physician behavior, hospital policies and real-time conditions such as intensive care unit capacity. Patients evaluated for admission to the intensive care unit during times of high intensive care unit capacity may have adverse outcomes related to delays in care.

While standardization can be a strategy for improving outcomes in the critical care setting, we do not recommend standardizing patient triage policy across hospitals given the different resources at different hospitals. Hospitals should develop local guidelines for patient triage taking into account their unique set of resources.

In order to optimize patient triage to the intensive care unit within hospitals, there should be a better matching of bed supply and demand. There may be opportunities for innovation, including the flexible use of inpatient beds, telemedicine-capable beds and mobile critical care teams.

\section{INTRODUCTION}

According to National Health Expenditure Accounts data, healthcare spending in the United States accounted for $17.9 \%$ of gross domestic product (GDP) in 2017 [1]. This number is projected to climb to $19.4 \%$ by 2027 [1], as healthcare spending is outpacing GDP growth. Critical care services are an expensive inpatient resource, accounting for $13 \%$ of hospital-related expenditures and $0.72 \%$ of GDP [2].

Intensive care units may be an attractive target for curbing healthcare spending in the
United States. Experts have proposed reducing the supply of intensive care unit beds as one potential intervention to decrease cost [3-5]. They argue that excess supply of critical care beds increases intensive care unit use by patients who may not benefit from it.

Professional societies have proposed criteria to guide triage to the intensive care unit [6-8], yet wide variation exists for many acute care conditions. This review describes the variation in utilization of intensive care unit beds. We summarize the evidence that exists with regard to which patients benefit from admission to the intensive care unit, as well as factors influencing patient triage decisions and patient outcomes, including bed availability. This review is based on previously conducted studies and did not require approval by the institutional review board.

\section{VARIATION IN UTILIZATION OF INTENSIVE CARE UNIT BEDS}

\section{Variation in Intensive Care Unit Admission Rates Among Hospitals in the United States}

There are robust data documenting the wide variation in intensive care unit admission rates among hospitals in the United States. A study using data from the Veterans Administration examined 289,310 patients from 118 hospitals in 48 states and revealed that $53.2 \%$ of patients admitted to the intensive care units of Veterans Administration hospitals had a predicted 30-day mortality of $\leq 2 \%$ [9]. Of these patients, the rate of intensive care unit admission ranged from 1.2 to $38.9 \%$ among hospitals [9]. These results indicate wide variation in admission patterns for patients with low likelihood of death among Veterans Administration hospitals. Similarly wide variation is reported in studies using other data sources [10-16].

Figure 1 depicts the theoretical relationship between likelihood of intensive care unit admission and patient severity of. As patient illness severity increases, the likelihood that a patient will be admitted to the intensive care unit increases. The dotted lines represent 


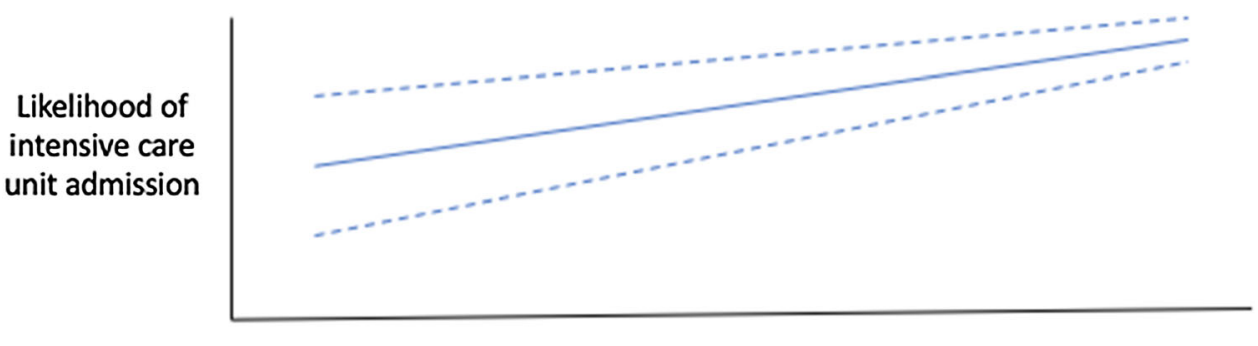

Patient severity of Illness

Fig. 1 Theoretical relationship between the likelihood of intensive care unit admission and patient severity of illness. The figure shows a positive relationship between patient severity of illness and likelihood of admission to the intensive care unit. The dotted lines represent confidence

confidence intervals. The confidence intervals are wider when a patient has lower severity of illness, because there is more variability in triage. The confidence intervals are narrower when a patient has higher severity of illness, because there are more definitive indications for admission to the intensive care unit.

\section{Variation in Intensive Care Unit Admission Rates Between Hospitals in the United States and Western Europe}

There are known differences in intensive care unit bed availability between countries. For example, fewer intensive care unit beds in the United Kingdom have been shown to be associated with fewer direct admissions from the emergency department, as well as longer hospital stays before admission and higher severity of illness [5]. There are also fewer intensive care unit admissions for terminal illness in the United Kingdom compared with the United States, despite similar overall hospitalization rates [17]. These results indicate that country-specific solutions are needed to optimize intensive care unit bed supply and demand.

\section{Variation in Intensive Care Unit Admissions for Patients with Specific Conditions}

Several studies have evaluated clinical outcomes when patients with acute care conditions are admitted to the intensive care unit versus general ward (Table 1). intervals. The confidence intervals are wider when a patient has lower severity of illness, due to variation in triage, and narrower when a patient has higher severity of illness, because of absolute indications for intensive care unit admission

Of the nine studies evaluating this issue, only one was a randomized controlled trial, and it was conducted in France. Guidet et al. developed a systematic triage tool and clusterrandomized 3037 elderly patients aged $\geq 75$ years with pneumonia to either the triage tool or usual care [18]. After adjusting for baseline characteristics, they found no difference in their primary outcome of death at 6 months between the intervention and control groups [18]. Interestingly, patients in the group triaged via the tool had a higher likelihood of being admitted to the intensive care unit. Secondary outcomes of functional status and physical quality of life also did not differ between the groups at 6 months [18].

The remaining eight studies were retrospective, using data sources such as Medicare, State Inpatient Database and Premier Healthcare Database. The analyses used standard risk adjustment techniques, including adjustment for severity of illness and extent of comorbidities. Some used causal inference techniques, such as instrumental variables, in order to address the issue of unmeasured confounding $[19,20]$. Only one study reported a statistically significant difference in long-term mortality for Medicare patients admitted with pneumonia [20]; Valley et al. reported a 5.7\% absolute increase in 30-day survival in elderly patients with pneumonia treated in the intensive care unit [20]. The authors employed the instrumental variable of differential distance between a low- and high-intensive care unit-utilizing 
Table 1 Summary of clinical studies demonstrating patient outcomes based on intensive care unit triage for various conditions

\begin{tabular}{|c|c|c|c|}
\hline Condition & Finding & Data source & References \\
\hline \multirow[t]{2}{*}{ Pneumonia } & $\begin{array}{l}5.7 \% \text { absolute } 30 \text {-day survival advantage with } \\
\text { equivalent cost for elderly patients admitted } \\
\text { to the ICU versus general ward }\end{array}$ & Medicare patients aged $>65$ years & {$[20]$} \\
\hline & $\begin{array}{l}\text { Equivalent } 6 \text {-month mortality for cluster- } \\
\text { randomized patients triaged with a systematic } \\
\text { triage tool versus usual care }\end{array}$ & $\begin{array}{l}\text { Randomized controlled trial } \\
\text { conducted in France of patients } \\
\text { aged }>65 \text { years }\end{array}$ & {$[18]$} \\
\hline $\begin{array}{l}\text { Chronic } \\
\text { obstructive }\end{array}$ & $\begin{array}{l}\text { Equivalent } 30 \text {-day mortality and cost per } \\
\text { hospitalization }\end{array}$ & Medicare patients aged $>65$ years & [19] \\
\hline $\begin{array}{l}\text { pulmonary } \\
\text { disease }\end{array}$ & $\begin{array}{l}\text { Equivalent in-hospital mortality rates, but patients } \\
\text { in hospitals with higher ICU admission rates } \\
\text { had higher rates of central venous lines and } \\
\text { arterial lines and higher cost per hospitalization } \\
\text { (\$1491) }\end{array}$ & $\begin{array}{l}\text { Twelve states from State Inpatient } \\
\text { Database, Agency for Healthcare } \\
\text { Research and Quality }\end{array}$ & {$[10]$} \\
\hline \multirow[t]{2}{*}{$\begin{array}{r}\text { Pulmonary } \\
\text { embolus }\end{array}$} & $\begin{array}{l}\text { Equivalent in-hospital mortality, cost per } \\
\text { hospitalization and readmission rate, but } \\
\text { patients in hospitals with higher ICU admission } \\
\text { rates had higher rates of mechanical ventilation, } \\
\text { noninvasive ventilation, central venous } \\
\text { catheterization and thrombolytic therapy }\end{array}$ & $\begin{array}{l}\text { Three states from State Inpatient } \\
\text { Database, Agency for Healthcare } \\
\text { Research and Quality }\end{array}$ & {$[13]$} \\
\hline & $\begin{array}{l}\text { Equivalent in-hospital mortality, but patients in } \\
\text { hospitals with higher ICU admission rates had } \\
\text { higher rates of central venous line placement } \\
\text { and thrombolysis and higher cost per } \\
\text { hospitalization }(\$ 457)\end{array}$ & $\begin{array}{l}\text { Two states from State Inpatient } \\
\text { Database, Agency for Healthcare } \\
\text { Research and Quality }\end{array}$ & {$[15]$} \\
\hline \multirow[t]{3}{*}{$\begin{array}{l}\text { Acute myocardial } \\
\text { infarction }\end{array}$} & $\begin{array}{l}\text { Equivalent } 30 \text {-day mortality for patients with } \\
\text { non-ST-elevation myocardial infarction } \\
\text { admitted to the ICU versus general ward at } \\
\text { high/intermediate- versus low ICU-utilizing } \\
\text { hospitals, even among high-risk patients }\end{array}$ & Medicare patients aged $>65$ years & {$[11]$} \\
\hline & $\begin{array}{l}\text { Equivalent 30-day mortality, but patients } \\
\text { admitted to the ICU had higher cost per } \\
\text { hospitalization }(\$ 4922)\end{array}$ & Medicare patients aged $>65$ years & [19] \\
\hline & $\begin{array}{l}\text { Equivalent in-hospital all-cause mortality by } \\
\text { treatment location, but patients in hospitals } \\
\text { with higher ICU admission rates had higher } \\
\text { rates of mechanical ventilation, vasopressors, } \\
\text { balloon pumps and pulmonary artery catheters }\end{array}$ & Premier Healthcare Database & {$[12]$} \\
\hline
\end{tabular}


Table 1 continued

\begin{tabular}{|c|c|c|c|}
\hline Condition & Finding & Data source & $\overline{\text { References }}$ \\
\hline \multirow[t]{3}{*}{$\begin{array}{l}\text { Congestive heart } \\
\text { failure }\end{array}$} & $\begin{array}{l}\text { Equivalent 30-day mortality, but patients } \\
\text { admitted to the ICU had higher cost per } \\
\text { hospitalization }(\$ 2608)\end{array}$ & Medicare patients aged $>65$ years & {$[19]$} \\
\hline & $\begin{array}{l}\text { Equivalent in-hospital mortality, but patients in } \\
\text { hospitals with higher ICU admission rates had } \\
\text { higher rates of central venous line placement } \\
\text { and pulmonary artery catheterization and } \\
\text { higher cost per hospitalization }(\$ 3412)\end{array}$ & $\begin{array}{l}\text { Two states from State Inpatient } \\
\text { Database, Agency for Healthcare } \\
\text { Research and Quality }\end{array}$ & {$[15]$} \\
\hline & $\begin{array}{l}\text { Equivalent in-hospital mortality; patients in } \\
\text { hospitals with higher ICU admission rates had } \\
\text { lower rates of mechanical ventilation, } \\
\text { noninvasive ventilation and vasopressors }\end{array}$ & Premier Healthcare Database & {$[16]$} \\
\hline \multirow[t]{2}{*}{$\begin{array}{l}\text { Diabetic } \\
\text { ketoacidosis }\end{array}$} & $\begin{array}{l}\text { Equivalent in-hospital mortality and length of } \\
\text { hospital stay for patients admitted to the ICU } \\
\text { versus general ward }\end{array}$ & $\begin{array}{l}\text { New York, State Inpatient Database, } \\
\text { Agency for Healthcare Research } \\
\text { and Quality }\end{array}$ & {$[14]$} \\
\hline & $\begin{array}{l}\text { Equivalent in-hospital mortality, but patients in } \\
\text { hospitals with higher ICU admission rates had } \\
\text { higher rates of central venous line placement } \\
\text { and mechanical ventilation and higher cost per } \\
\text { hospitalization }(\$ 1063)\end{array}$ & $\begin{array}{l}\text { Two states from State Inpatient } \\
\text { Database, Agency for Healthcare } \\
\text { Research and Quality }\end{array}$ & {$[15]$} \\
\hline $\begin{array}{l}\text { Upper } \\
\text { gastrointestinal } \\
\text { bleed }\end{array}$ & $\begin{array}{l}\text { Equivalent in-hospital mortality, but patients in } \\
\text { hospitals with higher ICU admission rates had } \\
\text { higher rates of central venous line placement } \\
\text { and esophagogastroduodenoscopy and higher } \\
\text { cost per hospitalization (\$687) }\end{array}$ & $\begin{array}{l}\text { Two states from State Inpatient } \\
\text { Database, Agency for Healthcare } \\
\text { Research and Quality }\end{array}$ & {$[15]$} \\
\hline
\end{tabular}

The only study showing a difference in clinical outcome by treatment location is highlighted in bold $I C U$ intensive care unit

hospital in order to study marginal patients, in which the decision to admit to the intensive care unit was discretionary [20].

Besides Valley et al. [20], the other retrospective studies listed in Table 1 showed equivalent in-hospital or 30-day post-discharge mortality. They evaluated patients with the following conditions: pneumonia, chronic obstructive pulmonary disease, pulmonary embolus, acute myocardial infarction, congestive heart failure, diabetic ketoacidosis and upper gastrointestinal bleed.
Of the nine studies listed in Table 1, three examined cost. For 7 of the 11 acute care conditions, there was potential cost savings per hospitalization if patients were treated on the general ward versus the intensive care unit. The amount saved per hospitalization ranged from $\$ 457$ for pulmonary embolus to $\$ 4922$ for acute myocardial infarction, although several studies notably showed no difference in cost.

Several of the studies also examined secondary outcomes, such as the likelihood of patients receiving invasive procedures. For example, Myers et al. showed that patients admitted to the 
intensive care unit with chronic obstructive pulmonary disease requiring noninvasive ventilation had higher rates of central venous lines and arterial lines [10]. Admon et al. showed that patients admitted to the intensive care unit with pulmonary embolus had higher rates of mechanical ventilation, noninvasive ventilation, central venous catheterization and thrombolysis [13]. Finally, Chang et al. showed that patients admitted to the intensive care unit with pulmonary embolus had higher rates of thrombolysis, patients with congestive heart failure were more likely to receive pulmonary artery catheterization, patients with diabetic ketoacidosis were more likely to receive a central venous line, and patients with upper gastrointestinal bleed were more likely to undergo esophagogastroduodenoscopy [15]. All of the interventions mentioned, however, are typically delivered in the critical care setting, so it is unclear from these retrospective analyses whether the interventions were necessary and prompted the appropriate transfer of the patients to the intensive care unit, or whether patients received these procedures for weaker indications because they had already been triaged to the intensive care unit.

In summary, based on the data summarized in Table 1, it appears that care for most conditions studied can be delivered safely on the general ward and potentially at lower cost. Treating patients on the general ward may even be beneficial in terms of protecting patients from unnecessary invasive procedures occurring in the intensive care unit, but the higher rates of such procedures occurring in patients admitted to the intensive care unit could be due to residual confounding. One specific patient population (elderly patients with pneumonia) may benefit from admission to the intensive care unit based on Valley et al. [20].

\section{PATIENT TRIAGE}

\section{Factors Influencing Patient Triage Decisions}

There are many factors influencing daily patient triage decisions, including physician behavior, hospital policies and real-time conditions such as intensive care unit capacity.
Physicians involved in patient triage have been shown to reduce both under-triage and over-triage to the intensive care unit [21], as well as improve patient throughput [22]. However, individual physicians' decisions to admit patients to the intensive care unit can vary. In a prospective observational trial performed in France, intensivists adhered to only 4 of 20 recommendations related to patient triage [23]. There was lower adherence to the recommendations when the intensive care unit was full or when triage was performed over the phone [23], suggesting that real-time capacity constraints do change clinicians' sense of transfer urgency. Other studies have confirmed that triage over the phone results in a lower likelihood of recommending transfer [24]. It is unclear what the best training is for optimal triage of patients. It is possible that clinical specialty matters less than skills in resource utilization, disaster management, communication and leadership.

Similarly, Valley et al. demonstrated poor agreement among intensivists when they were shown randomized clinical vignettes of patients with pneumonia and asked to estimate the benefit of transfer to the intensive care unit [25]. Some patient factors, such as age, were associated with higher likelihood of transfer, but race and ethnicity were not [25]. Other factors such as bed availability and presence of family at the bedside, which are typically unrelated to the severity of patient illness, were in fact associated with a likelihood of recommending transfer. Vignettes mentioning one open intensive care unit bed increased intensivists' likelihood of recommending transfer, whereas vignettes mentioning family at the bedside decreased intensivists' likelihood of recommending transfer [25].

Besides physician behavior, hospital-level policies contribute to the tendency for patients to be treated in an intensive care unit. Admon et al. used Medicare data to show that intensive care unit admission rates were positively correlated within hospitals regardless of the diagnosis (congestive heart failure, acute myocardial infarction, stroke, pneumonia, chronic obstructive pulmonary disease and hip fracture) [26]. The intraclass correlation coefficient was 0.38-0.59. After adjusting for patient characteristics, they reported that hospitals accounted 
for $17.6 \%$ of the variability in intensive care unit admission [26]. Another study using the State Inpatient Database similarly found that hospitals accounted for $19.7 \%$ of variation in patient admission to the intensive care unit [27]. Local policies guiding patient triage likely take into account the resources available at the hospital. Examples of resources include nighttime physician coverage, nurse-to-patient ratios and availability of respiratory therapy.

Lastly, dynamic variables such as real-time intensive care unit capacity also influence the tendency for patients to be admitted to the intensive care unit [28-32]. Anesi et al. examined retrospective hospital-level data from three hospitals in the University of Pennsylvania hospital system and reported a negative association between higher intensive care unit capacity and lower likelihood of patients with sepsis being admitted to the intensive care unit [29]. This finding was robust in multiple sensitivity analyses and after adjustment for patient characteristics as well as other "strain" variables, such as intensive care unit turnover, intensive care unit daily census and ward occupancy [29]. The authors interpreted this to mean that a $10 \%$ increase in intensive care unit occupancy was associated with a $13 \%$ decrease in the odds of admission to the intensive care unit [29].

In summary, an array of interrelated factors influence whether patients are treated in the intensive care unit. Many of these factors depend on bed availability at the time of triage and are not easily defined into a static algorithm.

\section{Association Between Intensive Care Unit Bed Supply and Patient Outcomes}

It is unclear whether this phenomenon of fewer available critical care beds causing lower likelihood of intensive care unit admission actually influences patient outcomes. Studies have reported mixed results.

For example, Stelfox et al. revealed that patients who developed sudden clinical deterioration on the general ward at a time when there were no available intensive care unit beds were $33.0 \%$ less likely to be admitted to the intensive care unit and $89.6 \%$ more likely to have their goals of care changed compared with patients whose condition deteriorated when $>$ 2 intensive care unit beds were available [28]. They did not detect a change in hospital mortality [28]. A study by Mery et al. corroborated these results using a different data source [30].

However, in a prospective observational study in France by Robert et al. [32], the authors found that patients admitted to the intensive care unit after being initially refused admission due to capacity constraints had higher 28-day and 60-day mortality [32]. Similarly, Anesi et al. found that patients with sepsis admitted to the general ward from the emergency department during times of higher intensive care unit occupancy had higher odds of in-hospital mortality (odds ratio 1.61, 95\% confidence interval 1.21-2.14) [29]. The results from both of these studies strongly suggest that not only are triage decisions influenced by capacity, but patient outcomes may suffer as a downstream consequence of denying access to the intensive care unit.

Although more research is needed on this topic, we should be aware that limiting the supply of intensive care unit beds in a hospital system that is already operating at capacity may have adverse effects on patient outcomes.

\section{SOLUTIONS FOR OPTIMIZING PATIENT OUTCOMES WITH REGARD TO TRIAGE}

\section{Standardizing Triage of Patients to Intensive Care Units Across Hospitals}

There are many documented examples of the benefits of standardizing practice in the healthcare setting [33]. One historical example in the critical care realm was the dramatic decrease in central line-associated bloodstream infections when a standardized protocol was implemented [34]. However, one could argue that a procedure to place a central line is more easily standardized across hospitals than patient triage, given the number of variables influencing triage decisions, including dynamic strain variables and the different resources existing in some rural community facilities. The Joint 
Commission on Accreditation of Healthcare Organizations requires that hospitals have a guideline for triage. We believe that it makes sense to continue making broad recommendations about patient triage, but that policy should be determined at the hospital level given the complex local environments that exist, especially in community hospitals [35].

\section{Alternative Approaches for Optimizing Patient Triage}

There may be alternative approaches for optimizing patient triage without constructing more beds or limiting patients' access. From a systems perspective, we could try to better match bed supply with bed demand. Because intensive care units have been built where there is more competition for business and not necessarily where there is more need for critical care services, experts have proposed requiring a "certificate of need" before new intensive care units can be built [36]. This policy may limit unnecessary growth in regions where demand is not high enough to warrant construction of additional beds.

Other solutions at the hospital level involve increasing the latent supply of critical care beds. This could be by (1) identifying and treating patients known to be at the end of life in more appropriate care settings and (2) identifying some beds and providers who could flex to provide critical care if there is a sudden increase in demand. Clinicians may be able to identify patients who are at the end of life and decide to manage them in inpatient hospice or a hospice house [17]. Limiting these patients' use of intensive care unit beds could reduce overall admissions to the intensive care unit, although some argue that the cost savings would be minimal due to the high fixed costs of operating intensive care units [37]. Alternatively, hospitals could designate one floor and a provider to be able to flex to take care of a critically ill patient if the demand increases on a certain day [38, 39]. This may require personnel to maintain certification in multiple areas of the hospital, which could have adverse safety implications if they are less familiar with the current treatment protocols. Another model might be a mobile critical care team of physicians and nurses who deliver short episodes of critical care on the general ward, such as a patient who needs a few hours of vasopressor therapy or noninvasive ventilation.

The use of intermediate care units has grown in the past decade, not only in the United States [40] but abroad as well [41, 42]. Intermediate care units, sometimes known as "high-dependency units", vary dramatically in terms of the types of patients they accept and their staffing structures and treatment capabilities [42, 43]. Some will focus on post-procedural cardiac patients, while others focus on patients with tracheostomy tubes. To our knowledge, no studies exist that indicate how the growth of these units has influenced critical care bed capacity, triage, cost and patient outcomes. However, they may be appropriate for various patient populations, such as patients needing increased attention from nursing or respiratory therapy or patients with chronic lung disease who are either in exacerbation or entering the end stages of their disease. There is some evidence that such units can save money [44, 45]. Bertolini et al. showed that the cost per patient in a respiratory intensive care unit was lower $(€ 754)$ than a regular intensive care unit $(€ 1507)$ [44]. Further research is needed.

Lastly, the advent of telemedicine capable facilities could enable general medicine beds to become a "ward plus" bed if vital sign monitoring is the only indication for admission to the intensive care unit [46-48]. More work is needed before this becomes a routine option instead of transferring patients to the intensive care unit for closer in-person monitoring.

\section{Stakeholders to Engage for Change in a Hospital's Patient Triage Process}

Implementing change related to patient triage policy would require input and engagement from multiple stakeholders.

There are many stakeholders involved in patient triage. Patients and families would likely prefer a higher level of monitoring up to the point when they theoretically receive unnecessary invasive procedures. Providers working under a fee-for-service model may prefer admitting more 
patients to the intensive care unit and performing more procedures, while salaried providers may prefer a higher threshold for admission to the intensive care unit. Hospitals are incentivized to fill existing intensive care unit beds because the reimbursement per day is higher than a general medicine bed, but insurers may refuse to pay for intensive care unit services without special documentation. Certainly, these differing viewpoints represent a complex environment for implementing change. Sponsorship from senior leadership would likely be required in order to make lasting changes to a hospital's triage policy.

\section{FINAL INSIGHTS}

We have summarized the evidence published to date on the variation in utilization of intensive care unit beds for several common acute conditions, the factors influencing patient triage and patient outcomes, including bed availability, and solutions for optimally triaging inpatients.

While one proposed method for decreasing intensive care unit cost is to limit supply, even relative and transient critical care bed shortages could have deleterious effects on patients who do not have absolute indications for intensive care unit admission. Matching country-specific bed supply with bed demand in terms of both timing of admissions (weekday, weekend, day, night) and geography (regions of the country, academic versus community medical centers, urban versus rural hospitals) may reduce cost on a systems level without negatively affecting patient outcomes. Furthermore, with the goal of providing safe, timely and efficient care in line with the Institute of Medicine's definition of high-quality healthcare [49], there may be an opportunity to innovate, such as implementing more flexible inpatient bed assignments, telemedicine-capable beds or mobile critical care teams.

\section{ACKNOWLEDGEMENTS}

Funding. No funding was obtained to prepare this publication.
Authorship. All named authors meet the International Committee of Medical Journal Editors (ICMJE) criteria for authorship for this article, take responsibility for the integrity of the work as a whole, and have given their approval for this version to be published.

Disclosures. Laura C. Myers, Gabriel Escobar and Vincent X. Liu have nothing to disclose.

Compliance with Ethics Guidelines. This review is based on previously conducted studies and did not contain any new studies with human participants. Approval by the Institutional Review Board was not required.

Data Availability. Data sharing is not applicable to this article, as no data sets were generated or analyzed during the current study.

Open Access. This article is distributed under the terms of the Creative Commons Attribution-NonCommercial 4.0 International License (http://creativecommons.org/licenses/ by-nc/4.0/), which permits any non-commercial use, distribution, and reproduction in any medium, provided you give appropriate credit to the original author(s) and the source, provide a link to the Creative Commons license, and indicate if changes were made.

\section{REFERENCES}

1. National Health Expenditure Data. Forecast summary. Baltimore, MD; 2018. https://www.cms.gov/ Research-Statistics-Data-and-Systems/StatisticsTrends-and-Reports/NationalHealthExpendData/ Downloads/ForecastSummary.pdf. Accessed Oct 23, 2019.

2. Society of Critical Care Medicine. Critical care statistics. Mount Prospect, IL; 2019. https://www. sccm.org/Communications/Critical-Care-Statistics. Accessed Oct 23, 2019.

3. Gooch RA, Kahn JM. ICU bed supply, utilization, and health care spending: an example of demand elasticity. JAMA. 2014;311(6):567-8.

4. Wunsch H, Angus DC, Harrison DA, Collange O, Fowler R, Hoste EA, et al. Variation in critical care 
services across North America and Western Europe. Crit Care Med. 2008;36(10):2787-93, e1-9.

5. Wunsch H, Angus DC, Harrison DA, Linde-Zwirble WT, Rowan KM. Comparison of medical admissions to intensive care units in the United States and United Kingdom. Am J Respir Crit Care Med. 2011;183(12):1666-73.

6. Dawson JA. Admission, discharge, and triage in critical care. Crit Care Clin. 1993;9(3):555-74.

7. Task Force of the American College of Critical Care Medicine and Society of Critical Care Medicine. Guidelines for intensive care unit admission, discharge, and triage. Crit Care Med. 1999;27(3):633-8.

8. Nates JL, Nunnally M, Kleinpell R, Blosser S, Goldner J, Birriel B, et al. ICU admission, discharge, and triage guidelines: a framework to enhance clinical operations, development of institutional policies, and further research. Crit Care Med. 2016;44(8):1553-602.

9. Chen LM, Render M, Sales A, Kennedy EH, Wiitala $\mathrm{W}$, Hofer TP. Intensive care unit admitting patterns in the Veterans Affairs health care system. Arch Intern Med. 2012;172(16):1220-6.

10. Myers LC, Faridi MK, Currier P, Camargo CA Jr. ICU utilization for patients with acute exacerbation of chronic obstructive pulmonary disease receiving noninvasive ventilation. Crit Care Med. 2019;47(5): 677-84.

11. Fanaroff AC, Peterson ED, Chen AY, Thomas L, Doll JA, Fordyce CB, et al. Intensive care unit utilization and mortality among medicare patients hospitalized with non-ST-segment elevation myocardial infarction. JAMA Cardiol. 2017;2(1):36-44.

12. Chen R, Strait KM, Dharmarajan K, Li SX, Ranasinghe I, Martin J, et al. Hospital variation in admission to intensive care units for patients with acute myocardial infarction. Am Heart J. 2015;170(6):1161-9.

13. Admon AJ, Seymour CW, Gershengorn HB, Wunsch $\mathrm{H}$, Cooke CR. Hospital-level variation in ICU admission and critical care procedures for patients hospitalized for pulmonary embolism. Chest. 2014;146(6):1452-61.

14. Gershengorn HB, Iwashyna TJ, Cooke CR, Scales DC, Kahn JM, Wunsch H. Variation in use of intensive care for adults with diabetic ketoacidosis. Crit Care Med. 2012;40(7):2009-15.

15. Chang DW, Shapiro MF. Association between intensive care unit utilization during hospitalization and costs, use of invasive procedures, and mortality. JAMA Intern Med. 2016;176(10):1492-9.
16. Safavi KC, Dharmarajan K, Kim N, Strait KM, Li SX, Chen SI, et al. Variation exists in rates of admission to intensive care units for heart failure patients across hospitals in the United States. Circulation. 2013;127(8):923-9.

17. Wunsch H, Linde-Zwirble WT, Harrison DA, Barnato $\mathrm{AE}$, Rowan $\mathrm{KM}$, Angus DC. Use of intensive care services during terminal hospitalizations in England and the United States. Am J Respir Crit Care Med. 2009;180(9):875-80.

18. Guidet B, Leblanc G, Simon T, Woimant M, Quenot $\mathrm{JP}$, Ganansia $\mathrm{O}$, et al. Effect of systematic intensive care unit triage on long-term mortality among critically ill elderly patients in France: a randomized clinical trial. JAMA. 2017;318(15):1450-9.

19. Valley TS, Sjoding MW, Ryan AM, Iwashyna TJ, Cooke CR. Intensive care unit admission and survival among older patients with chronic obstructive pulmonary disease, heart failure, or myocardial infarction. Ann Am Thorac Soc. 2017;14(6):943-51.

20. Valley TS, Sjoding MW, Ryan AM, Iwashyna TJ, Cooke CR. Association of intensive care unit admission with mortality among older patients with pneumonia. JAMA. 2015;314(12):1272-9.

21. Rehn M, Eken T, Kruger AJ, Steen PA, Skaga NO, Lossius HM. Precision of field triage in patients brought to a trauma centre after introducing trauma team activation guidelines. Scand J Trauma Resusc Emerg Med. 2009;17:1.

22. Howell E, Bessman E, Marshall R, Wright S. Hospitalist bed management effecting throughput from the emergency department to the intensive care unit. J Crit Care. 2010;25(2):184-9.

23. Azoulay E, Pochard F, Chevret S, Vinsonneau C, Garrouste M, Cohen Y, et al. Compliance with triage to intensive care recommendations. Crit Care Med. 2001;29(11):2132-6.

24. Garrouste-Orgeas M, Montuclard L, Timsit JF, Misset $\mathrm{B}$, Christias M, Carlet J. Triaging patients to the ICU: a pilot study of factors influencing admission decisions and patient outcomes. Intensive Care Med. 2003;29(5):774-81.

25. Valley TS, Admon AJ, Zahuranec DB, Garland A, Fagerlin A, Iwashyna TJ. Estimating ICU benefit: a randomized study of physicians. Crit Care Med. 2019;47(1):62-8.

26. Admon AJ, Wunsch $\mathrm{H}$, Iwashyna TJ, Cooke CR. Hospital contributions to variability in the use of ICUs among elderly Medicare recipients. Crit Care Med. 2017;45(1):75-84. 
27. Seymour CW, Iwashyna TJ, Ehlenbach WJ, Wunsch $\mathrm{H}$, Cooke CR. Hospital-level variation in the use of intensive care. Health Serv Res. 2012;47(5): 2060-80.

28. Stelfox HT, Hemmelgarn BR, Bagshaw SM, Gao S, Doig CJ, Nijssen-Jordan C, et al. Intensive care unit bed availability and outcomes for hospitalized patients with sudden clinical deterioration. Arch Intern Med. 2012;172(6):467-74.

29. Anesi GL, Liu VX, Gabler NB, Delgado MK, Kohn R, Weissman GE, et al. Associations of intensive care unit capacity strain with disposition and outcomes of patients with sepsis presenting to the emergency department. Ann Am Thorac Soc. 2018;15(11): 1328-35.

30. Mery E, Kahn JM. Does space make waste? The influence of ICU bed capacity on admission decisions. Crit Care. 2013;17(3):315.

31. Sprung CL, Geber D, Eidelman LA, Baras M, Pizov R, Nimrod A, et al. Evaluation of triage decisions for intensive care admission. Crit Care Med. 1999;27(6):1073-9.

32. Robert R, Reignier J, Tournoux-Facon C, Boulain T, Lesieur $\mathrm{O}$, Gissot V, et al. Refusal of intensive care unit admission due to a full unit: impact on mortality. Am J Respir Crit Care Med. 2012;185(10): 1081-7.

33. Haynes AB, Weiser TG, Berry WR, Lipsitz SR, Breizat $\mathrm{AH}$, Dellinger EP, et al. A surgical safety checklist to reduce morbidity and mortality in a global population. N Engl J Med. 2009;360(5):491-9.

34. Pronovost P, Needham D, Berenholtz S, Sinopoli D, $\mathrm{Chu} \mathrm{H}$, Cosgrove $\mathrm{S}$, et al. An intervention to decrease catheter-related bloodstream infections in the ICU. N Engl J Med. 2006;355(26):2725-32.

35. The Joint Commission on the Accreditation of Healthcare Organizations. Standards Information for Hospitals. Oakbrook Terrace, IL; 2019. https:// www.jointcommission.org/accreditation/hap_ standards_information.aspx. Accessed Oct 19, 2019.

36. Wallace DJ, Angus DC, Seymour CW, Barnato AE, Kahn JM. Critical care bed growth in the United States. A comparison of regional and national trends. Am J Respir Crit Care Med. 2015;191(4): 410-6.

37. Luce JM, Rubenfeld GD. Can health care costs be reduced by limiting intensive care at the end of life? Am J Respir Crit Care Med. 2002;165(6):750-4.

38. Carr BG, Addyson DK, Kahn JM. Variation in critical care beds per capita in the United States: implications for pandemic and disaster planning. JAMA. 2010;303(14):1371-2.

39. Manuell ME, Co MD, Ellison RT 3rd. Pandemic influenza: implications for preparation and delivery of critical care services. J Intensive Care Med. 2011;26(6):347-67.

40. Sjoding MW, Valley TS, Prescott HC, Wunsch H, Iwashyna TJ, Cooke CR. Rising billing for intermediate intensive care among hospitalized Medicare beneficiaries between 1996 and 2010. Am J Respir Crit Care Med. 2016;193(2):163-70.

41. Scala R, Corrado A, Confalonieri M, Marchese S, Ambrosino N. Increased number and expertise of Italian respiratory high-dependency care units: the second national survey. Respir Care. 2011;56(8): 1100-7.

42. Plate JDJ, Leenen LPH, Houwert M, Hietbrink F. Utilisation of intermediate care units: a systematic review. Crit Care Res Pract. 2017;2017:8038460.

43. Confalonieri M, Gorini M, Ambrosino N, Mollica C, Corrado A, Scientific Group on Respiratory Intensive Care of the Italian Association of Hospital P. Respiratory intensive care units in Italy: a national census and prospective cohort study. Thorax. 2001;56(5):373-8.

44. Bertolini G, Confalonieri M, Rossi C, Rossi G, Simini B, Gorini M, et al. Costs of the COPD. Differences between intensive care unit and respiratory intermediate care unit. Respir Med. 2005;99(7): 894-900.

45. Plate JDJ, Peelen LM, Leenen LPH, Hietbrink F. The intermediate care unit as a cost-reducing critical care facility in tertiary referral hospitals: a singlecentre observational study. BMJ Open. 2019;9(6): e026359.

46. Kahn JM, Hill NS, Lilly CM, Angus DC, Jacobi J, Rubenfeld GD, et al. The research agenda in ICU telemedicine: a statement from the Critical Care Societies Collaborative. Chest. 2011;140(1):230-8.

47. Young LB, Chan PS, Lu X, Nallamothu BK, Sasson C, Cram PM. Impact of telemedicine intensive care unit coverage on patient outcomes: a systematic review and meta-analysis. Arch Intern Med. 2011;171(6):498-506.

48. Wilcox ME, Adhikari NK. The effect of telemedicine in critically ill patients: systematic review and metaanalysis. Crit Care. 2012;16(4):R127.

49. Institute of Medicine Committee on Quality of Healthcare in America. Crossing the quality chasm: a new health system for the 21st century. Washington, D.C.: National Academy Press; 2001. 